\title{
Posterior Reversible Encephalopathy Syndrome Causing Transient Postoperative Blindness Following Spine Surgery
}

\author{
Meenupriya Arasu' ${ }^{1, \odot}$ Srinivasan Swaminathan ${ }^{1}$ \\ ${ }^{1}$ Department of Anaesthesiology, Jawaharlal Institute of \\ Postgraduate Medical Education and Research, Puducherry, India
}

\author{
Balaji Kannamani ${ }^{1} \quad$ Lenin B. Elakkumanan ${ }^{1}$
}

J Neuroanaesthesiol Crit Care 2022;9:58-59.

Postoperative vision loss (POVL) is devastating not only for the patient but also for the anesthesiologist. Posterior reversible encephalopathy syndrome (PRES) is an infrequent and treatable cause of POVL, which is reported predominantly in rapid hemodynamic perturbations, endothelial dysfunction, and massive volume resuscitation. ${ }^{1,2}$ To our knowledge, there are no reported cases of PRES following acute hypertension for a brief duration of 3 minutes and massive transfusion.

A 55-year-old female with a body mass index (BMI) of $21.82 \mathrm{~kg} / \mathrm{m}^{2}$, belonging to the American Society of Anesthesiologists (ASA) physical status class I, underwent posterior spine instrumentation (T8-L4) for correction of kyphoscoliosis. She was positioned prone for 9 hours under general anesthesia on a conventional orthopedic operating table, with soft chest and pelvic supports. Her head was positioned neutrally on a doughnut, and eye compression was circumvented by periodic confirmation of adequate periorbital space. Motor and somatosensory-evoked potential recorded no abnormal signals. Anesthesia was maintained with propofol infusion (75-100 $\mathrm{mcg} / \mathrm{kg} / \mathrm{min})$, fentanyl $(0.5-1 \mathrm{mcg} / \mathrm{kg} / \mathrm{h})$, and isoflurane (end-tidal $<0.5 \%$ ) to allow optimal neurophysiological and entropy (target 40-60) monitoring. Normothermia was maintained. Ventilation was targeted to an end-tidal carbon-dioxide of 30 to $40 \mathrm{~mm} \mathrm{Hg}$ and oxygen saturation $>94 \%$. Intraoperatively, there was a drop in hematocrit to $25 \%$ from a baseline of $30 \%$. Active resuscitation with crystalloids and blood products was initiated immediately. During resuscitation, there was a transient fall in arterial blood pressure (BP) to $70 / 40 \mathrm{~mm} \mathrm{Hg}$ for 5 minutes. Noradrenaline infusion was initiated at 0.02 to $0.04 \mathrm{mcg} / \mathrm{kg} / \mathrm{min}$. Subsequently, there was an episode of acute rise of systolic BP to $190 \mathrm{~mm} \mathrm{Hg}$, presumably due to an inadvertent bolus delivery of noradrenaline
Address for correspondence Srinivasan Swaminathan, MD, DNB, Department of Anaesthesiology, Jawaharlal Institute of Postgraduate Medical Education and Research, Puducherry 605006, India (e-mail: srinianaes@yahoo.co.in).

from the infusion pump. Noradrenaline was stopped immediately and propofol bolus was administered. BP normalized to $120 / 80 \mathrm{~mm} \mathrm{Hg}$ in 3 minutes, and remained within normal range thereafter. Five packs of red blood cells $(1250 \mathrm{~mL})$, plasma (1000 mL), and $4000 \mathrm{~mL}$ of crystalloids were administered to cope with the total blood loss of $2000 \mathrm{~mL}$ and urine output of $2000 \mathrm{~mL}$. The hematocrit was raised to $33 \%$ in the next hour. Due to prolonged prone positioning, postoperative mechanical ventilation was planned, anticipating airway edema. Two hours after shifting the patient to the postoperative unit, two episodes of generalized seizures occurred and were treated with phenytoin (1 $\mathrm{g}$ intravenous [IV] followed by $100 \mathrm{mg}$ IV tid) and levetiracetam (500 mg IV bd). She had a persistent staring look. Blood sugar and electrolytes were normal. CT brain ruled out cerebral hemorrhage and edema, which were suspected due to the acute intraoperative hypertension and prolonged prone position. ${ }^{3}$ On the first postoperative day, there were no seizures, and extubation of trachea was done. Postextubation, she complained of painless vision loss bilaterally. Ophthalmic examination revealed bilateral loss of light perception and impaired optokinetic nystagmus, denoting a cortical pathology. ${ }^{4}$ Fundus and light reflex were normal, indicating an intact pathway till midbrain. ${ }^{5}$ Other causes of POVL like ischemic optic neuropathy (ION) and central retinal artery occlusion (CRAO) were ruled out by the absence of relative afferent pupillary defect and normal findings in fundus. The constellation of symptoms of seizures, altered sensorium, blindness and the association with acute intraoperative hypertension, and volume resuscitation directed toward the suspicion of PRES. ${ }^{1,2}$ MRI of the brain ( $\mathbf{- F i g}$. 1A,B) depicted typical bilateral symmetrical T2 hyperintensities in the watershed zones of published online October 24, 2021
DOI https://doi.org/

$10.1055 / \mathrm{s}-0041-1731919$ ISSN 2348-0548
(C) 2021. Indian Society of Neuroanaesthesiology and Critical Care. All rights reserved.

This is an open access article published by Thieme under the terms of the Creative Commons Attribution-NonDerivative-NonCommercial-License, permitting copying and reproduction so long as the original work is given appropriate credit. Contents may not be used for commercial purposes, or adapted, remixed, transformed or built upon. (https://creativecommons.org/licenses/by-nc-nd/4.0/).

Thieme Medical and Scientific Publishers Pvt. Ltd. A-12, 2nd Floor, Sector 2, Noida-201301 UP, India 

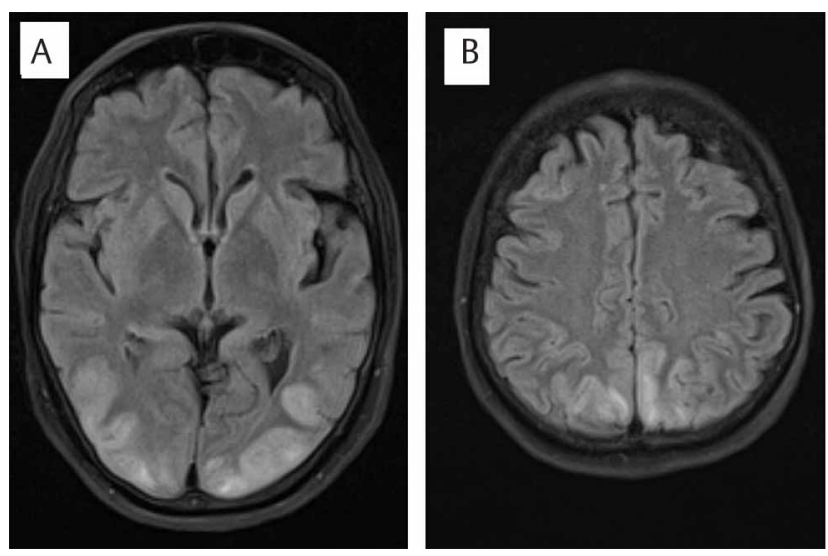

Fig. 1 (A, B) MRI brain-fluid attenuation inversion recovery (FLAIR) sequence in axial plane, showing hyperintensities in bilateral parietal and occipital lobes suggestive of posterior reversible encephalopathy syndrome (PRES).

occipital and parietal lobes, confirming PRES. Mannitol (20 g IV tid), head-end elevation, and antiepileptics were continued. On the third postoperative day, the vision recovered completely, and she was discharged a week later.

PRES is a vasogenic edema reported in cases of hypertensive emergencies, eclampsia, renal failure, cytotoxic chemotherapy, immunosuppressants, transplant recipients, and massive transfusion..$^{1,2}$ Gopalakrishnan et al have reported PRES following sustained elevation in blood pressure. ${ }^{6}$ Singh et al reported PRES due to a sudden increase in blood viscosity following rapid blood transfusion in cases of uterine fibroid with menorrhagia. ${ }^{2}$ The endotheliopathy precipitated by acute hemorrhagic shock could lead to a disruption in the blood-brain barrier (BBB). Although the exact pathophysiology remains unclear, disruption of the BBB and fluid extravasation due to acute hypertension exceeding the cerebral autoregulation threshold or endothelial dysfunction remains the most accepted mechanism. ${ }^{1,2,7}$ In our case, although the episode of hypertension was transient, the association with endotheliopathy from rapid volume resuscitation could have been the precipitating cause of PRES. The typical neuroradiological findings in MRI with bilateral and symmetrical parieto-occipital involvement were consistent with the diagnosis of PRES. POVL following spine surgery may result from CRAO, central retinal vein occlusion (CRVO), ION, cortical blindness, PRES, acute glaucoma, or corneal abrasion. Most of the causes except ION are potentially reversible if diagnosed and treated early. Having a low threshold of suspicion is cardinal for expeditious treatment of the reversible causes and prevention of permanent or secondary neurological injury.

\section{Acknowledgment}

The authors wish to thank Malavika Mani, Senior Resident, Department of Ophthalmology, Jawaharlal Institute of Postgraduate Medical Education and Research, Puducherry.

\section{Conflict of Interest}

None declared.

\section{References}

1 Fugate JE, Rabinstein AA. Posterior reversible encephalopathy syndrome: clinical and radiological manifestations, pathophysiology, and outstanding questions. Lancet Neurol 2015;14(9):914-925

2 Singh K, Gupta R, Kamal H, Silvestri NJ, Wolfe GI. Posterior reversible encephalopathy syndrome secondary to blood transfusion. J Clin Neurosci 2015;22(3):592-594

3 Roth C, Ferbert A, Deinsberger W, et al. Does prone positioning increase intracranial pressure? A retrospective analysis of patients with acute brain injury and acute respiratory failure. Neurocrit Care 2014;21(2):186-191

4 Frost EA. Visual loss after anesthesia different causes: different solutions-a review. Middle East J Anaesthesiol 2010;20(5):639-648

5 Wilhelm H, Kardon RH. The pupillary light reflex pathway. J Neuroophthalmol 1997;17:59-62

6 Gopalakrishnan CV, Vikas V, Nair S. Posterior reversible encephalopathy syndrome in a case of postoperative spinal extradural haematoma: case report and review of literature. Asian Spine J 2011;5(1):64-67

7 Anderson RC, Patel V, Sheikh-Bahaei N, et al. Posterior reversible encephalopathy syndrome (PRES): pathophysiology and neuro-imaging. Front Neurol 2020;11:463 